\title{
MÁQUINA DE GUERRA E INFÂNCIA "ENTRE": NOTAS SOBRE A DESTERRITORIALIZAÇÃO DA INFÂNCIA CONTEMPORÂNEA
}

\author{
Helena Almeida e Silva Sampaio ${ }^{\mathrm{i}}$
}

\begin{abstract}
Resumo: Este artigo parte de uma perspectiva sobre infância e criança pautada em Deleuze e Guattari, utilizando deles o conceito de "máquina de guerra" como uma forma de pensar a criação de novos espaços-tempos para suscitar acontecimentos e desterritorializar a infância contemporânea. Busca-se aqui, então, traçar uma linha "entre" os pontos fixos, numa tentativa de irromper a realidade e abrir espaço nas afirmações, prescrições e avaliações que "desabam" sobre as crianças, não apenas incluídas no ideal hegemônico de infância, mas governadas por dispositivos de subjetivação de um "Homo oeconomicus" - o sujeito neoliberal -, agente em um jogo econômico de produção e consumo de liberdades, segundo os estudos de Michel Foucault. Para inventar outros mundos educativos possíveis, num contexto contemporâneo e neoliberal, requer-se a possibilidade de se pensar uma infância "entre", de modo a tirar a criança da dicotomia incluída/excluída da infância.
\end{abstract}

Palavras-chave: Acontecimentos; Educação; Infância; Máquina de guerra.

\section{MÁQUINA DE GUERRA Y NIÑEZ "ENTRE": NOTAS SOBRE LA ESTERRITORIALIZACIÓN DE LA NIÑEZ CONTEMPORÁNEA}

Resumen: Este artículo parte de una perspectiva sobre niñez y niño pautada en Deleuze y Guattari, utilizándose del concepto de "máquina de guerra" como una forma de pensar la creación de nuevos espacios-tiempos para suscitar acontecimientos y desterritorializar la niñez contemporánea. Se busca, entonces, trazar una línea "entre" los puntos fijos, intentando irrumpir la realidad y abrir un hueco en las afirmaciones, prescripciones y evaluaciones que se "derrumban" sobre los niños, no sólo incluidos en el ideal hegemónico de niñez, pero también gobernados por los dispositivos de subjetivación de un "Homo oeconomicus" -el sujeto neoliberal-, agente en un juego económico de producción y consumo de liberdades, según los estudios de M. Foucault. Para inventarse otros mundos educativos posibles, dentro de un contexto contemporáneo y neoliberal, hace falta la posibilidad de uno pensar una niñez "entre", con vistas a sacar el niño de la dicotomía incluido/excluido (de la niñez).

Palabras-clave: Acontecimientos; Educación; Niñez; Máquina de guerra.

\section{Introdução}

Ante a incapacidade de dar conta da complexidade desta realidade, na qual até parece ser "inútil revoltar-se",ii, urge-nos a necessidade de limitar o poder, de construir barreirasiii quando este se mostra tão opressivo... Mas como? "[...] Acreditar no mundo significa principalmente suscitar acontecimentos, mesmo pequenos, que escapem ao controle, ou engendrar novos espaços-tempos, mesmo de superficie e volume reduzidos " (DELEUZE, 2013, 


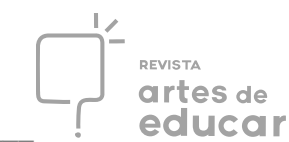

p. 220, grifo nosso). Haveria então, um acontecimento que pudesse engendrar um novo espaçotempo para pensar uma infância, capaz de não a fazer desabar sobre as crianças de um modo tão prescritivo?

Deleuze e Guatarri (1997b) parecem indicar as máquinas de guerra como um modo de criar uma forma de ocupar o espaço-tempo e de inventar novos espaços-tempo. Para eles, " $a$ máquina de guerra é exterior ao aparelho de Estado" (DELEUZE; GUATTARI, 1997b, p. 7), e com isso, não queremos nos referir apenas ao Estado como a entidade burocrática governamental moderna, mas também a própria ideia de "estado das coisas", de aparatos que produzem e reproduzem modelos e ordenam o mundo por meio de uma "estaticidade" - um desejo de não mudança, uma força "antidevir".

A máquina de guerra (nômade) faz frente aos aparatos sedentários e busca transbordálos. São máquinas que, mesmo se capturadas pelos aparelhos de Estado, podem enxamear outras "máquinas de pensar, de amar, de morrer, de criar, que dispõem de forças vivas ou revolucionárias suscetíveis de colocar em questão o Estado triunfante" (DELEUZE; GUATTARI, 1997b, p. 18). Também podem ser uma forma de "promover novas formas de subjetividade através da recusa deste tipo de individualidade que nos foi imposto há vários séculos" (FOUCAULT, 1995b, p. 239).

Essas máquinas de guerra, então, saberiam saborear e escapar às capturas, elas também trincariam as infâncias "molares" e fariam a linguagem dominante ou "maior" gaguejariv . Nessa artimanha gaguejante, estremeceria aquela fixidez enunciativa que pode dizer, da infância, "isso é...”. Assim, uma máquina de guerra poético-filosófica colocaria a infância num “entre-ser” e, por isso, faria surgir uma "zona de vizinhança" na qual, da infância e da criança, já não se podia dizer "isso é" sem que se gaguejasse, sem que algo escapasse outra vez pela janela da casa construída, "a correr e a rolar-se pela erva e a arrancar flores para as deitar fora e a rir de modo a ouvir-se de longe" (PESSOA, 2016, p. 32). Quiçá, a estratégia de poetizar a infância faria um bloco (de carnaval) poético, um "bloco de infância" e, finalmente, abriria alas para outra criança passar:

A esta altura (provavelmente ou possivelmente) o leitor pergunta: - Onde vamos chegar?

— Seguramente não sei, mas sigamos. — Respondo, em seguida lançando o convite E que tal desapegar daquela ânsia de tudo interpretar? Que tal experimentar?

Experimenta que era a... presença duma máquina de guerra filosófica capaz de desterritorializar o desejo dominante de que $a$ infância e $a$ criança tenham contornos pontuais Revista Interinstitucional Artes de Educar. Rio de Janeiro, V. 7, N. 1 - pág. 60-81 janeiro-abril de 2021: "Pedagogias Vitais: Corpo, Desejo e Educação" DOI: 10.12957/riae.2021.54910 
e bem definidos numa paisagem, num território cristalizado.

Experimenta que era um... convite a pensar uma infância "menor", avessa às formas de identificação e codificação porque linhas de fuga não deixam limitá-la à forma padrão majoritária, a manter-se como $a$ infância "maior"v

Aproveita o ensejo e experimenta que era o... fomentar de um flerte com a dúvida, que alivia a incômoda obrigação de ter razão, que bagunça as teorias e propõe "sacudir os hábitos, as maneiras de fazer e de pensar, dissipar as familiaridades aceitas" (FOUCAULT, 2006, p. 249), a desnaturalizar o óbvio ao ponto de referir-se à uma infância sem o uso de expressões como "sabe-se que", ou "todos sabemos que", ou "como já sabemos", pois "quando todo mundo sabe, ninguém sabe" (KOHAN, 2004, p. 1) ${ }^{\mathrm{vi}}$.

\section{Uma máquina de guerra filosófica}

Desemaranhar, desfiar, destramar, destecer, cardar... Reduzir a fios aquilo que era tomado como "a" verdade absoluta, como "o" conceito inquestionável, como "a" infância transcendental, para experimentar novos alinhavos com as linhas afectivas de pensamento e de escrita. Exercitar a capacidade da escrita de uma pesquisa porque "a palavra oral não dá rascunho "vii. Tomar a pesquisa como uma força que age sobre os corpos e não como substância ou substantivo que se pode possuir, dar ou receber. Uma pesquisa produzida numa intensidade de movimentos que escapam ao mero digitar dessas frases, porque já reverberam no corpo, na fala, nas ações e gestos, nas sensações... Finalmente, sentir na pesquisa qual a medida para fazer do devir "um verbo tendo toda sua consistência" (DELEUZE; GUATTARI, 1997a, p. 20). Porque também, de certa maneira,

[...] é preciso começar pelo fim: todos os devires já são moleculares. É que devir não é imitar algo ou alguém, identificar-se com ele. Tampouco é proporcionar relações formais. Nenhuma dessas duas figuras de analogia convém ao devir, nem a imitação de um sujeito, nem a proporcionalidade de uma forma. Devir é, a partir das formas que se tem, do sujeito que se é, dos órgãos que se possui ou das funções que se preenche, extrair partículas, entre as quais instauramos relações de movimento e repouso, de velocidade e lentidão, as mais próximas daquilo que estamos em vias de devir, e através das quais devimos. É nesse sentido que o devir é o processo do desejo (DELEUZE; GUATTARI, 1997a, p. 67).

Numa polinização de devires, houve um devir-clandestino da pesquisadora, um devir do objeto de pesquisa, um devir dessa própria escrita viii (ou seria um bloco de devir: Revista Interinstitucional Artes de Educar. Rio de Janeiro, V. 7, N. 1 - pág. 60-81 janeiro-abril de 2021: "Pedagogias Vitais: Corpo, Desejo e Educação" DOI: 10.12957/riae.2021.54910 


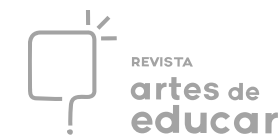

pesquisadora-pesquisa-infância-escrita-linhas-filosofia-poesia-e...?). Como nunca, aproximome de um exercício de pensamento rizomático, que se move e se abre, explode em todas as direções, pressupondo pensar a tensão como rizoma, não como árvore. "A árvore impõe o verbo 'ser', mas o rizoma tem como tecido a conjunção 'e... e... e...'”' (DELEUZE; GUATTARI, 2000, p. 36).

Assim como Deleuze e Guattari arrastaram-me de meu território, agora arrasto-os para um outro território. Como na associação entre a vespa e a orquídea ${ }^{\mathrm{ix}}$, co-evoluímos na imanência de uma pesquisa, fazemos rizomas de nossas heterogeneidades, co-presenciamos possibilidades e conjunções e... De modo que agora, desterritorializando-a, penso a criança, que no percurso da metamorfose nietzschiana do espírito vem depois do camelo e do leão ${ }^{\mathrm{x}}$,

[...] como uma força ativa que cria, produz, inventa, varia, a criança é uma força que impulsiona a vida. Matéria não-formada. Infância informe. Hecceidade. Individuações pré-individuais. Matilha de afectos. Moleculares, menores. É pura intensão de fluxos, de energéticas, de forças. Multiplicidades incessantes. Artistagens de vida. Nomadizações. Capazes de romper, percolar, infiltrar, dissolver, fraturar, trincar as formas molares e "maiores", como aquelas dos adultos, dos homens, dos heterossexuais, dos brancos, dos bem falantes da língua... Tudo escapa, tudo foge. Essa infância é a criança em ato. Tempo da criança é o tempo da criação. Da ação. Criando. Criançando. Podercriança (CHIQUITO, 2014, p. 21).

Com o esquizo-desejo de experimentar uma infância-menor, cria-se uma máquina de guerra que anseia assumir um "devir todo mundo", pois quer "ir ao encontro do Mundo, ou confundir-se com ele. [Sair] de casa no fio de uma cançãozinha." (DELEUZE; GUATTARI, 1997a, p. 123) Porém, ainda que motivada em traçar outras tantas linhas de vida possíveis, essa máquina de guerra - abrindo alas - questiona: o que cresce entre infância e a criança? Se uma linha de devir passasse entre esses dois pontos (infância e criança), ela produziria neles uma desterritorialização que (nos) arrastaria a ambos? E o que passaria "entre as duas, levando-as para uma vizinhança comum onde desaparece a discernibilidade dos pontos" (DELEUZE; GUATTARI, 1997a, p. 96)?

Sem qualquer pretensão de encontrar respostas a tais questões, há a empolgação de improvisar $^{\mathrm{xi}}$ com, em arrastar-se Deleuze e Guattari para (ajudarem a) pensar isso. Ao relê-los, descobri que "um sistema será dito pontual enquanto as linhas forem consideradas nele como coordenadas, ou como ligações localizáveis” (DELEUZE; GUATTARI, 1997a, p. 97). Além disso, se o devir também é "um movimento pelo qual a linha libera-se do ponto" (DELEUZE; GUATTARI, 1997a, p.96), liberar a linha de um sistema pontual o faz devir um sistema 
multilinear:

[...] um sistema pontual será mais interessante à medida que um músico, um pintor, um escritor, um filósofo, [um educador?] se oponha a ela, e até o fabrique para opor-se a ele, como um trampolim para saltar. A história só é feita por aqueles que se opõem à história (e não por aqueles que se inserem nela, ou mesmo a remanejam. Não é por provocação, mas porque o sistema pontual, que encontravam todo pronto ou que eles próprios inventavam, devia permitir essa operação: liberar a linha e a diagonal, traçar a linha em vez de coordenadas, produzir uma diagonal imperceptível, em vez de agarrar a uma vertical e a uma horizontal mesmo que complicadas ou reformadas. Isso recai sempre na História, mas nunca veio dela. (DELEUZE; GUATTARI, 1997a, p. 99)

Portanto, ao que parece, liberando-se infância e criança das concepções sócio-históricas e das concepções médico-psicopedagógica-econômica-etc., que fazem delas transcendentais históricos, se poderia liberar infância e criança da condição de pontos (como origem ou chegada). Isso permitiria reposicioná-las de forma avessa às coordenadas horizontais e verticais típicas dos sistemas pontuais (ou de arborescências). Se poderia, então, "liberar a diagonal”, do mesmo modo que "não há músico nem pintor que não tenham essa intenção" (DELEUZE; GUATTARI, 1997a, p. 99), ou seja, pensá-las a partir de agenciamentos multilineares e diagonais. Pensá-las, sobretudo, diante das criações que "são como linhas abstratas mutantes que se livraram da incumbência de representar um mundo, precisamente porque elas agenciam um novo tipo de realidade que a história só pode recuperar ou recolocar nos sistemas pontuais" (DELEUZE; GUATTARI, 1997a, p. 100).

Assim como na pintura (e em seu "bloco de cor"), entre o branco vertical e o negro horizontal, só poderá surgir "o cinza de Klee, o vermelho de Kandinsky, o violeta de Monet" (DELEUZE; GUATTARI, 1997a, p. 103), há entre o infante e o adulto uma diagonal criança (e seu bloco de devir), porque não é um ponto que marca a origem e que faz a linha, é a linha que arrasta o ponto para sua influência exterior:

a linha não vai de um ponto a outro, mas entre os pontos ela corre numa outra direção que os torna indiscerníveis. A linha deveio diagonal que se liberal da vertical e da horizontal; mas a diagonal já deveio a transversal, a semidiagonal ou a direita livre, a linha quebrada ou angular, ou então a curva, sempre no meio delas mesmas. (DELEUZE; GUATTARI, 1997a, p. 102)

Buscamos, assim, formas de sair dos dualismos, articular ideias para destituir as máquinas binárias de produção do real. Ele quer resistir, quer liberar o conceito de infância das prisões que lhe impuseram. É uma máquina que se move quando cria, quando experimenta Revista Interinstitucional Artes de Educar. Rio de Janeiro, V. 7, N. 1 - pág. 60-81 janeiro-abril de 2021: "Pedagogias Vitais: Corpo, Desejo e Educação" DOI: 10.12957/riae.2021.54910 


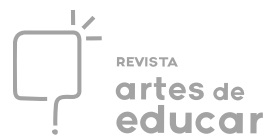

desvios contra às formas de captura "maiores", quando esburaca as convicções, quando estabelece conexões múltiplas com o mundo. Uma máquina adepta ao ímpeto nômade de “desvelar no invisivel o visível nele velado” (LINS, 2014, p. 141), como artifício para dissolver as tentativas de padronização e estandartização que ofuscam os saberes, fazeres, poderes.

E, ao seguir por um território, num contexto contemporâneo e neoliberal, essa máquina de guerra encontra "crianças": algumas percebidas como a "alma do negócio"xii , denominadas como "público-alvo", expostas aos mais variados tipos de apelos, pois são parte de um nicho de mercado, e, a desabar sobre elas, uma infância governada por dispositivos de subjetivação de um "Homo oeconomicus" (FOUCAULT, 2008). Outras, excluídas de tais atributos, riscadas do status social reconhecido da infância, crianças à margem daquela normatividade. Seriam as crianças tematizadas por Marchi (2007) como "não-crianças"xiii , pois não se encaixam nos atributos, desígnios, representações, prescrições, interesses, enfim; tudo aquilo que compõe a ideia dominante do que é "ser criança". São "não-crianças" porque "não-são", porque não figuram o que é regido e considerado pelo estatuto social, econômico e simbólico daquela infância.

Diante disso, nossa máquina de guerra segue obstinada, quer fazer vibrar numa infânciaoutra uma "hecceidade" (DELEUZE; GUATTARI, 1997a), ou seja, "um modo de individuação específica que constitui individualidades novas e resiste à prisão identitária regida pelo pensamento ontológico" (FURTADO; LINS, 2008, p.52). Desta maneira, a partir da noção de "hecceidade", posso seguir pensando uma infância num entre-lugar, pois como um acontecimento que escapa a si mesmo, ela não poderia ser aprisionada em um tempo único e por um sentido universal inscrito subjetivamente, verbalmente, moralmente...

Torna-se urgente questionar todas as formas de reduzir os múltiplos modos de existência, de comportamento, de corporeidades, de significações... Pensar em individuações frente à individualização moderna (e neoliberal) da criança.

Em suma, entre as formas substanciais e os sujeitos determinados, entre os dois, não há somente todo um exercício de transportes locais demoníacos, mas um jogo natural de hecceidades, graus, intensidades, acontecimentos, acidentes, que compõem individuações, inteiramente diferentes daquelas dos sujeitos bem formados que as recebem. (DELEUZE; GUATTARI, 1997a, p. 40)

— "Eis a força do pensamento deleuziano: injeções de prudência nas efetuações de nossos experimentos" (FURTADO; LINS, 2008, p. 52) - alertar-me-ia um experiente filósofo em experiências. Ele ainda emendaria pedindo-me certo cuidado com o que significa "sujeitos Revista Interinstitucional Artes de Educar. Rio de Janeiro, V. 7, N. 1 - pág. 60-81 janeiro-abril de 2021: "Pedagogias Vitais: Corpo, Desejo e Educação" DOI: 10.12957/riae.2021.54910 
bem formados". Explicar-me-ia sobre a importância de romper com a visão cartesiana de consciência, pautada na razão, de perceber que com Deleuze e Guattari (1997a), propõe-se pensar em possibilidades de subjetivação que não estão vinculadas às noções de consciência da psicologia moderna ou de uma razão transcendente.

A esta outra altura, quer saber o que pude aprender com os aventureiros nômades "que nunca fui”? Vamos lá:

- "Os espaços de vizinhança antecedem as casas, e quanto mais potentes são as zonas de vizinhança, menos muros precisam ter as casas" (SOUZA, 2015, ON-LINE).

Imageticamente, portanto, será que se poderia retirar uma tal "infância-muro" ou rever a zona de vizinhança em que se construiu uma criança-casa? Talvez. Ou então sequer saiu-se do lugar comum com toda essa filosofia... Por outro lado, perguntar, experimentar que era, ousar desmanchar o tecido e refazer a costura soam como pistas de como as perguntas das crianças podem ser mais bem compreendidas e para que se comece a enxergar nelas perguntasmáquinas ${ }^{\mathrm{xiv}} \ldots$ Talvez.

Não se rompe com o esquema de arborescência, não se atinge o devir e nem o molecular, enquanto uma linha for remetida a dois pontos distantes, ou for composta de pontos contíguos. Uma linha de devir não se define nem por pontos que ela liga nem por pontos que a compõem: ao contrário, ela passa entre os pontos, ela só cresce pelo meio, e corre numa direção perpendicular aos pontos que distinguimos primeiro, transversal à relação localizável entre pontos contíguos ou distantes (DELEUZE; GUATTARI, 1997a, p. 95).

Portanto, ao que parece, experimentar combinações impossíveis como retirar a infância e a criança de seus muros ou dos esquemas de arborescências ou ainda, da condição de pontos submissos à uma linha, poderiam produzir alguma variação e diferença em ambas (e em nós)...

— Mas como? Como fazer um "bloco de infância”, um "devir-criança”?

- Num "movimento pelo qual a linha libera-se do ponto, e torna os pontos indiscerniveis: rizoma, o oposto da arborescência, livrar-se da arborescência”, balbuciariam Deleuze e Guattari (1997a, p .96), contagiando a ponto de seguir-se remendando mais um retalho no pensar.

E “de novo recorremos às crianças” (DELEUZE; GUATTARI, 1997a, p. 45) e... e... e... para ensaiar pensá-las, desta vez, em duas alas distintas: com seus modos de existência (ou seriam tendências?) dentro de uma "organização" (ou seria um partido?) reconhecida médicopedagógico-econômico e socialmente como: infância.

— Mas, espere aí! Essa máquina de guerra não buscava formas de sair dos dualismos? Revista Interinstitucional Artes de Educar. Rio de Janeiro, V. 7, N. 1 - pág. 60-81 janeiro-abril de 2021: "Pedagogias Vitais: Corpo, Desejo e Educação" DOI: 10.12957/riae.2021.54910 
— me perguntaria o leitor exigente, atrás do pluralismo que esta máquina promete...

Eu respondo: - Calma! Trata-se apenas de uma estratégia para abrir caminhos...para mover-me entre. "Vamos pra avenida, desfilar a vida, carnavalizar?” (TRIBALISTAS, 2002). Ô abre alas, que a máquina de guerra quer passar ${ }^{\mathrm{xv}}$ !

\section{A ala da criança incluída na infância}

Se dispuséssemos as crianças em alas, certamente a mais evidente seria aquela da criança incluída na infância (ou portadora dela). Nesta ala, as crianças incluídas, reconhecidas, contempladas, visíveis, alvos...

Deste lado, alguns exemplos dos traços mais perversos, das especificidades para pensar sobre quais seriam os "atributos" partilhados pela nossa sociedade que incluem as crianças no âmbito de uma "infância maior".

Para compor essa descrição, elenco duas citações: a primeira, tomo emprestado de Sylvio Gadelha da Costa (2009) quando ele menciona em um de seus artigos, a citação do Nobel de Economia, Theodore Schultz, que em 1973 (apud COSTA, 2009, p.172), afirmou: "uma classe particular de capital humano, consistente do 'capital configurado na criança', pode ser a chave de uma teoria econômica da população”; a segunda é de Benjamin Barber (2009, p. 32), quando faz um alerta sobre a perversidade de que $a$ infância vem padecendo: "para $o$ capitalismo de consumo prevalecer é preciso tornar as crianças consumidores e tornar os consumidores crianças".

Desse modo, creio já ser possível articular como as "crianças" que estão incluídas na “infância maior”, são vítimas de um sem-número de artefatos, de práticas (discursivas e nãodiscursivas) que as tomam não só como "sujeitos de direitos" - como pode-se ler em documentos oficiais e estatutos -, mas como alunos de instituições escolares, como pacientes de clínicas médicas e psicopedagógicas, mas, sobretudo, como potenciais consumidoras.

Soma-se a isso, o discurso da publicidade televisiva que agora conta com "pedagogias especializadas baseadas em meios digitais e virtuais" (MILL, 2013, p. 87), para difundir a compra de insumos tecnológicos, videogames, portais de informação, programas de simulação e robótica - um conjunto de produtos que cria um mercado infantil tecnologizado e que passa a prezar "por uma sociedade de infantilização do homem e não apenas da criança" (MILL, 2013, p. 87). 
Desenha-se aqui, portanto, uma ínfima amostra da lógica de exploração midiática, comercial, tecnológica que "desabam” sobre as crianças que desfrutam do ideal hegemônico de infância. As quais, cabe reforçar, ainda podem frequentar diariamente uma escola que, numa esfera privada, por exemplo, também pode lucrar com novas matrículas quando vislumbra e planeja a formação de crianças bilíngues porque futuras empreendedoras. Eis a chamada "cultura do empreendedorismo" que já assola o campo educacional (COSTA, 2009), uma amostra de como:

determinados valores econômicos, à medida que migraram da economia para outros domínios da vida social, disseminando-se socialmente, ganharam um forte poder normativo, instituindo processos e políticas de subjetivação que vêm transformando sujeitos de direitos em indivíduos-microempresas empreendedores (COSTA, 2009, p. 172).

Diante do consumismo voltado para a infância, Gadelha (2010) sugere não só um governo das crianças, mas um governo dos adultos por meio do consumo infantil ${ }^{\mathrm{xvi}}$. E segue com a infantilização do adulto, selecionando da infância elementos que tornem os adultos governáveis por meio do consumo - uma estupidificação dos sujeitos (MILL, 2013). Mas se isto já representa um extremo dessa imagem da criança, qual seria o outro extremo dessa perversidade no trato com a criança nesse ethos neoliberal?

\section{Intermezzo $^{\mathrm{xvii}}$}

Às mil voltas com livros, artigos, grifos, palpites e orientações; invadiam-me as dúvidas. Chegavam a causar dor em meu corpo porque atravessavam-me a todo tempo. Eu tentava organizar as ideias para pensar sobre como atuaria uma tal máquina de guerra que adentrasse o território da Filosofia e me ajudasse a performar, a experimentar que eu era uma navegante errante... Uma transeunte entre uma quantidade de materiais, de afectos $^{\mathrm{x} v i i i}$, de devires.

E, em meio ao temporal, acalmam-se as tormentas. A chuva cai quando leio Daniel Lins (2017) escrevendo sobre Nietzsche e sobre uma estadia sem lugar. Ali ele parecia me ouvir. Acalentava-me com a potência de seus arranjos, de sua escrita. Era como se respondesse às perguntas que eu tinha vontade de fazer, que fariam parte daquele álbum de fotografias que comecei a montar depois das viagens nômades (que nunca fiz). Com certa empolgação, remexia nas páginas daquele texto com um pedido em mente: 
— Diga, por favor, Seu Lins, que tanto busca o pensamento nômade?

E ele respondeu:

Que busca o pensamento nômade? Não busca. Encontra. Encontro que permite conceber os processos de subjetivação como blocos de realidade, força artística, estética pensante, estética como acontecimento, realidade - e não verdade -, arte movediça engendradora de conceitos para um fazer filosófico complexo, múltiplo. Híbrido, o pensamento nômade encontra sua força no Eterno Retorno, e no conceito de super-homem, pois, ambos inspiram estudiosos de Nietzsche a elaborar um pensamento sem imagem canônica ou um sujeito teórico nômade que escapa ao modo de pensamento logocêntrico do racionalismo clássico. (LINS, 2017, p. 271)

Encontro $^{\text {xix }}$. Há, no entanto, uma sensação de que ainda faltava uma questão anterior à esta. Tinha a impressão de que eu, a suposta nômade "só de livro", imersa no caos, precisava reconhecer-me (minimamente), como alguém mais "avizinhada" desse povo. Como se isso não só me autorizasse a pensar com um toque de nomadismo, mas a extrapolar os próprios limites de minha escrita. Novamente, imaginei replicar:

— Mas afinal, que é o nômade?

Outra vez, Seu Lins respondeu:

Que é o nômade? Que estamos a chamar 'Pensamento Nômade'? O nômade é alguém cuja força crescente se desenvolve em um espaço aberto e liso no qual recua a floresta e cresce o deserto; em um espaço sem partilha, sem fronteiras nem cercas ou clausuras; é uma espécie de No man's land ou Terra de ninguém. É no prolongamento da filosofia nietzschiana que se pode desenvolver a ideia de 'sujeito' nômade cuja subjetividade - processos de subjetivação - se desenvolve como meio caminho entre suas pulsões inconscientes e determinações culturais, em um lugar de contradições que escapa à consciência e a sua razão. O sujeito nômade é uma imagem performativa que se distingue do modo de pensar dominante, agente político que remete a um desejo intenso de transgredir as fronteiras e estender os limites tornando-os 'Terra de ninguém'. (LINS, 2017, p. 272)

$\mathrm{Na}$ “Terra de Ninguém”, num lugar de contradições e de uma desrazão, reposicionei minha máquina de guerra, tratando-a de maneira mais ordinária, tratando-a como "se escuta um disco, como se vê um filme ou um programa de televisão, como se recebe uma canção" (DELEUZE; PARNET, 1998, p. 11). Era agora, uma máquina de guerra da "pop’philosophie", contaminada com a noção de que "não há nada a compreender, nada a interpretar" (DELEUZE; PARNET, 1998, p. 12) mas sim, achar diversificadas formas de se relacionar com o presente e infectar/afectar aquele "pensamento que só pensa o que deve ser pensado" (LINS, 2005, p. 1231). Eu ouvi o ritornelo: "Jamais interprete, experimente..." (DELEUZE, 2013, p. Revista Interinstitucional Artes de Educar. Rio de Janeiro, V. 7, N. 1 - pág. 60-81 janeiro-abril de 2021: "Pedagogias Vitais: Corpo, Desejo e Educação" DOI: 10.12957/riae.2021.54910 
111).

Olhando para uma criança "como irredutivel à visão de um adulto em miniatura e a afirmação de um presente da infância, que é devir e não simplesmente uma preparação para a vida adulta" (LINS, 2005, p. 1230, grifo no original), essa máquina de guerra - recalibrada por uma filosofia do movimento, do deslocamento - sai em busca de transformar os parâmetros do pensamento:

O que é a filosofia senão uma maneira de refletir, não exatamente sobre o que é verdadeiro e sobre o que é falso, mas sobre nossa relação com a verdade? Lamenta-se às vezes que não haja filosofia dominante na França. Tanto melhor. Nenhuma filosofia soberana, é verdade, mas uma filosofia, ou melhor, a filosofia em atividade. É filosofia o movimento pelo qual, não sem esforços, hesitações, sonhos e ilusões, nos separamos daquilo que é adquirido como verdadeiro, e buscamos outras regras de jogo. É filosofia o deslocamento e a transformação dos parâmetros de pensamento, a modificação dos valores recebidos e todo o trabalho que se faz para pensar de outra maneira, para fazer outra coisa, para tornar-se diferente do que se é (FOUCAULT, 2001, p. 929).

Disponível a muitas "conversações"”x (mesmo sem saber se farão parte da guerra ou já da paz), nossa máquina de guerra mal dobrou a esquina e pudemos ler na banca uma manchete de jornal com a frase em negrito: "Crianças fora da infância”. Compartilho abaixo a notícia na íntegra:

A FOLHA de 24 de junho de 2009 (caderno Cotidiano) relatou uma estranha decisão do Supremo Tribunal de Justiça.

Em Mato Grasso do Sul, em 2003, dois adultos, Zequinha Barbosa e Luiz Otávio F. da Anunciação, encontraram num ponto de ônibus, contrataram e levaram para um motel três moças que, na época, tinham 13, 14 e 15 anos. De uma delas, Anunciação tirou e armazenou fotos pornográficas. Em 2004, em primeira instância, Barbosa e Anunciação foram condenados, respectivamente, a cinco e sete anos de reclusão. Recorreram e, no ano seguinte, foram absolvidos pelo Tribunal de Justiça. Barbosa alegou que não participou do sexo, e Anunciação que ele não sabia que as garotas eram menores de 18 anos. Foi a vez da Procuradoria recorrer, e a coisa chegou ao Supremo Tribunal de Justiça, que decidiu assim: Anunciação é culpado por ter armazenado imagens pornográficas de uma menor, mas ele e Barbosa são absolvidos do crime de ter tido relações sexuais com menores. Por quê? Porque o Tribunal "considerou que não é crime manter relações sexuais com menores de 18 anos que sejam prostitutas". Ou seja, como não foram eles que "iniciaram" as meninas (ao sexo e à prostituição), eles não têm culpa. Curiosa contradição: se não é crime transar com uma menor que já transou, não se entende por que seria crime tirar e armazenar fotos pornográficas da mesma menor. Afinal, vai ver que alguém já tirou uma foto dela no passado. Mas isso é o de menos. Na linha de pensamento do STJ, também não haveria por que proibir o trabalho de crianças que já pediram esmola no farol -afinal, já trabalharam, não é? Da mesma forma, não seria crime estuprar uma mulher que já foi estuprada. E o 
que acontece com assaltar alguém que já foi assaltado? Ainda bem que, por sorte, não dá para matar alguém que já foi morto. A decisão do STJ não é uma excentricidade. Ao contrário, ela é reveladora de uma verdade que está escondida atrás de nossa "proteção" da criança e do adolescente. Nossa cultura decidiu separar as crianças dos adultos. Instituímos, por assim dizer, a infância como tempo da vida que deveria ser protegido tanto das necessidades (crianças não devem ganhar seu pão) quanto do desejo (chegamos a negar a sexualidade infantil). Tudo isso, aos poucos, acabou amparando efetivamente as crianças, mas a intenção inicial não era, propriamente, a de lhes reservar um destino melhor. Tratava-se de responder a uma necessidade dos adultos: mais ou menos duzentos anos atrás, com a progressiva crise de nossa fé no além e na eternidade das almas, as crianças se tornaram oficialmente nossa grande (e talvez única) garantia de continuidade, se não de eternidade. Morremos, e as crianças têm a missão de dar seguimento à nossa vida. Claro, gostaríamos que nosso futuro fosse melhor que nosso presente, portanto queremos que as crianças encenem, para nosso contentamento, uma visão de paraíso que compense nosso purgatório ou inferno cotidianos. Qual melhor consolação, para nós, cujas esperanças foram frustradas, do que a de contemplar nas crianças a felicidade que nos escapa? Somos infelizes e a vida é dura? Pois bem, faremos o que é preciso para que as crianças sejam (ou pareçam) felizes. Em suma, amamos nas crianças apenas um sonho de nosso próprio futuro. $\mathrm{E}$ as crianças que não são "aptas" a encenar esse sonho não são propriamente crianças, pois o que definiria as crianças (as que queremos proteger) não seria sua idade, mas sua capacidade de encenar uma infância feliz. Pois bem, a decisão do STJ é fiel a essa inspiração originária de nossa cultura: pouco importa que ela tenha $12,13,15$ anos ou menos, uma menor que se vende num ponto de ônibus já não tem mais como encenar para nós a vinheta da infância feliz. Portanto, ela não é mais "criança". Transar com ela não é mais transar com uma criança, não é? Essa lógica, aliás, vale para todas as crianças que, por uma razão ou outra, não podem mais (se é que um dia puderam) encenar o cartão postal sorridente que chamamos infância - por exemplo, as que encontramos nas esquinas ou dormindo debaixo das marquises de nossas ruas. Em suma, o STJ decidiu como se quisesse proteger não as crianças (como manda a letra da lei), mas o mito da infância. A Procuradoria recorrerá. Veremos como decidirá o Supremo Tribunal Federal. (CALLIGARIS, 2009, ON-LINE)

\section{A ala da não-criança porque excluída da infância (?)}

Um olhar acerca das perversidades em ato sobre as crianças ou sobre as "não-crianças" porque excluídas de uma "infância mito" (ou do que chamamos anteriormente de "infância maior"), não só racha - em profundidade - o emprego usual da palavra "criança" neste momento da pesquisa, mas recai como um martírio sobre esta pesquisadora.

Debato-me. Perco-me. Fico sem saber por onde, quando, como, de que forma, tratar, dar lugar a esta dura percepção. Sinto-me a falcatrua, a legítima "aventureira-nômade-só-de-livro", pois tentar escrever sobre quem comporia essa "ala", além de inserir (outra vez) uma 
perspectiva adulta ao texto, faz-me pesar que falar em nome das crianças ou da infância "é arrogar-nos um conhecimento ilimitado e acabado de causa” (MARCHI, 2007, p.24).

Nessa ala, a "não-criança", as excluídas, as não-reconhecidas, as não-contempladas, as invisíveis, as que não são alvo do mercado (ou seriam um alvo indireto?), mas são alvos da polícia, dos pedófilos, das assistentes sociais, das igrejas... São também as "crianças que não desfrutam da infância por conta de sua situação sócio-econômica” (MARCHI, 2007, p. 231), no qual sua imagem de "não-crianças" lhes é atribuída dada a não correspondência às características (sociais, econômicas e simbólicas) que compõem a imagem dominante do "ser criança".

Deste lado, a criança "fora" da infância como anuncia a notícia do jornal. Ou seriam “as crianças que não são 'aptas' a encenar [o] sonho não são propriamente crianças, pois o que definiria as crianças (as que queremos proteger) não seria sua idade, mas sua capacidade de encenar uma infância feliz" (CALLIGARIS, 2009, ON-LINE)?

Aos convertidos a lógica "maior" do pensamento dualista, seria possível dizer que a infância não é nem ser feliz, nem não o ser; que "ser criança” não se resume à uma faixa etária. Ponto Final. Doutro modo, aos profanos abertos ao pensamento nômade, seria possível ponderar sobre a importância de deslocar as afirmações, tirar a criança apenas da perspectiva biológica e a infância da condição de mito, de ser a que deve "encenar o cartão postal sorridente" (CALLIGARIS, 2009, ON-LINE) ou seu negativo (espelhado). Vírgula.

Com um modesto ímpeto nômade atravessando o detalhar desta ala, surge uma certa inquietação diante de uma análise mais atenta sobre a forma com que palavra "fora" foi utilizada naquela notícia. Especialmente, quando esta palavra sugere a (óbvia) condição: se há a criança "fora" da infância, imediatamente induz-se a pensar que haveria a criança "dentro" da infância. E isto, parece fazer sentido diante da estratégia das "alas" aqui propostas. No entanto, pensar sobre os pares "incluídas-excluídas" e "dentro-fora" marcando, assim, qual criança estaria incluída na "infância maior", portanto, "dentro" dela; e, no seu inverso, marcando qual criança ("não-criança") estaria excluída da "infância maior", portanto, "fora" dela; faz pensar sobre a possibilidade de que ambas “opções” fazem parte de um "grande dentro". Tal reflexão, ajuda a ponderar que não há um lugar de isenção, um "fora" em relação ao poder exercido pela “infância maior”.

Pensar sobre crianças e "não-crianças", portanto, num "grande dentro", poderia trazer à luz algumas das práticas mais cotidianas do poder ou mesmo, suas capilaridades, suas articulações produtivas e constitutivas, como também poderia dar visibilidade à algumas Revista Interinstitucional Artes de Educar. Rio de Janeiro, V. 7, N. 1 - pág. 60-81 janeiro-abril de 2021: "Pedagogias Vitais: Corpo, Desejo e Educação" DOI: 10.12957/riae.2021.54910 
perversas simetrias:

A "não-criança" é a imagem perversamente simétrica da "criança sujeito de direitos": a autonomia de que desfruta não é consequiência da expansão dos seus direitos, mas da sua privação. $\mathrm{O}$ seu processo de individualização não passa pelo seu acesso à cidadania, mas por sua exclusão desta condição (MARCHI, 2007, p. 15).

Mas como escapar à lógica do dentro e do fora? Seria possível situar infância(s) e crianças nas fronteiras?

\section{A máquina de guerra abre-alas para uma ética crianceira passar...}

Quando se adentra pelo território da filosofia “lê-se sempre no seu frontispício: 'Tudo pode ser de outra maneira'. Se não for, não há o que pensar" (KOHAN, 2015, p. 217, grifo nosso). Essa máquina de guerra, então, nos afastaria da afirmativa de que hoje pode-se pensar em crianças e "não-crianças" com infância ou "sem-infância", recolocando a possibilidade do pensamento. Esse deslocamento é parte do desejo de criar seus próprios conceitos ${ }^{\mathrm{xxi}}$, desejo de propor o exercício de rasgar o caos, de ensaiar um détournement de perspectiva; um desejo de abrir espaço nas afirmações e avaliações da criança "incluída" ou "excluída", um desejo de pensar (e criar) uma infância entre. Para isso, carrega a força de pensar num 'nem isso, nem aquilo', a importância de abster ou suspender um primeiro juízo, de não esboçar uma rápida opinião. Dedicou-se, então, em avaliar a situação daquelas "alas" pautando-se numa perspectiva da "infância do pensamento", na qual a ignorância tem vários significados possíveis:

[...] ela é ausência de saber, mas também é o saber afirmativo que não aceita o que "todo mundo" considera saber; é não querer saber o que, nem como, todo mundo sabe. Então, no mundo filosófico da infância, o mais sábio não sabe. Não sabe o saber que não se sabe a si mesmo e não sabe outro saber que o saber de querer sempre saber. A ignorância deixou de ser ausência, carência e insuficiência para tornar-se potência e motor dos possíveis. (KOHAN, 2015, p. 219)

Se estamos impregnados com a sua ânsia de experimentar, é também para colocar-nos num tête-à-tête com a sua ignorância, repotencializando-a. Para lidar com as carências mais evidentes, optou-se por acionar o "motor dos possíveis". No entanto, sentiu-se que era preciso rever o referencial teórico, abrir outros livros, outras possíveis leituras, cortar as raízes e fazer 
rizomas... Ou se deveria arrojar, agora, com uma "divisão de touceiras"?xxii

Para tanto, antes de ponderar outras perspectivas de análise, se quis dar ouvidos àquela que se sente entre um processo de pesquisa de uma infância, de uma criança. Por onde 'passaria a régua' da pesquisadora? Que crivo ético se encontra na infância de seu pensamento?

[P]ensar de verdade, pensar-se a si mesmo, fazer da filosofia a um exercício de se colocar a si mesmo em questão exige, a cada momento, ir até a mais recôndita infância do pensamento, começar a pensar tudo de novo como se nunca tivéssemos pensado, como se, a cada vez, estivéssemos pensando pela primeira vez. Assim, a infância é quase uma condição da filosofia. (KOHAN, 2015, p. 217)

A técnica de divisão de touceiras, de dividir o rizoma para fazer brotar, remete à noção de instaurar uma fratura "entre" a forma habitual e específica de ler e opinar sobre uma notícia de jornal, por exemplo, e lê-la pela ótica dessa máquina de guerra para experimentar outras "verdades" - ou outras relações com a verdade. "Liberar diagonais" numa costura diagonal de pontos, a partir daquilo que assume o lugar de dúvida, que traz a ignorância como potência para então, questionar: que outras formas de se pensar a infância para "fora" da criança, que não fazendo da própria criança um sujeito ou um substantivo, haveria? Como não esvaziar a infância da criança, mas liberar a infância da adultez, de um sujeito, de um substantivo, de uma substância?

Sobre os saberes que a quase tudo pretendem responder, estendem-se colchas de multiplicidade de retalhos, que favorecem arranjos e rearranjos de outros possíveis. Sem a possibilidade de totalizações ou universalismos, usar as colchas de retalhos como forma de adaptar pedaços distintos entre si com infinitas experimentações das combinações possíveis. Um "patchwork" (DELEUZE; GUATTARI, 1997b) e transformações, sabendo-se

[...] que não se cria sem a diversidade, sem o confronto com as diferenças, sem a atenção e o cuidado com cada retalho até que ele possa estar preparado para ligar-se aos demais. Também implica abertura para novos retalhos, na potência de um trabalho que comporta o inacabado ou na consciência de um tempo que não é o cronológico, que pode dilatar- se entre passado, presente e futuro. Mas, para que tudo isso ocorra, é preciso de um corpo que una, que tome a agulha e a linha, e enfrente uma costura que, talvez, tenha que ser refeita, repetidamente refeita, até que possamos olhá-la e nos reconhecermos nela. (RIZZO; FONSECA, 2010, p. 147)

Sobre as "alas" que bem reviraram essa máquina do avesso, desdobram-se colchas de 
retalhos conceituais para uma vez mais, se experimentar o engajamento "num processo do qual desconhece a saída e o resultado, e é nisso que ele está profundamente vinculado à experiência do novo. O novo não é a eternidade, é a invenção" (LINS, 2005, p. 1254). Para que, numa infância do pensamento, num constante vir a ser, se possa reinventar "um sujeito não sujeitado, não mais refém de uma identidade nem estruturado numa determinação que tudo 'resolve', sem se importar com os devires" (LINS, 2005, p. 1248).

Diante de tudo disso, experimentamos "abrir alas" para uma "ética-crianceira" passar... (Eis o ethos filosófico que atravessa esta escrita criando o seu próprio conceito). Uma ética que, feito uma arte equilibrista, atravessa por entre as alas, arrastando-as de lá... Um conceito que não quer pensar qualquer sorte de teoria da infância, ou de tomar a criança como objeto/sujeito da filosofia da infância, muito menos de uma ciência (humana) que encerraria a criança dentro de sua expertise. Já a opção pelo neologismo "crianceira" busca permitir pensar a criança fora da infância - de certa infância que governa a criança de certos modos, por certos sujeitos e para certos fins -, permite escapar ao peso e à dureza das palavras "infante", "infância", "infantil" que desabados sobre a palavra "criança" dificultam pensá-la enquanto potência e não impotência. Ainda que não corresponda totalmente, o neologismo é inspirado no termo “crianceria” que Chaim S. Katz (1993) utiliza em seu texto "Crianceria: o que é a criança”, para diferenciar aquilo que diz respeito a um "devir-criança" (potência da crianceria) e aquilo que é um "vir-a-ser" da criança, que passa da impotência à potência ao tornar-se adulta.

$\mathrm{Na}$ "ética-crianceira", a criança não seria sequer sujeito ou substantivo, o que demandaria outra relação com a criança, na qual não cabe a busca por 'domesticá-la', mas antes tomá-la como força e verbo: “criançar". Nem biológica, nem histórica, nem social e sim, criança-devir e criança-intempestiva e criança-metamorfose e criança-contágio e...e...e...

Assim, não se trata de pensar numa ética (mais ou menos utópica) que console a todos e encerre a questão em uma derradeira "estética da existência", mas uma prática atenta e refletida em que se preze pela abertura de espaço para a criação e para a invenção.

Uma ética que ao desobedecer ${ }^{\mathrm{xxiv}}$ a lógica de mercado, suspenda o valor de investimento e renda, e permita outros valores aparecerem. Uma ética que possa suscitar modos de vida não fascistas $^{\mathrm{xxv}}$, diante desse "outro fascismo" que assola a realidade, que suga para dentro de si toda a diferenciação produzida, que "mesmerizaria" a diferença e faz o Outro tornar-se "Mesmo".

Uma ética que, sobretudo, arranque a criança desse lugar sujeito ao adulto (biológico, médico, psicológico, pedagógico, histórico, social etc.) e torne-a força de renovação do mundo 


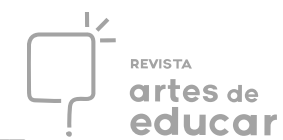

(ARENDT, 2016) e devir criador e uma forma de contágio (DELEUZE; GUATTARI, 1997a; 1997b; 2000) e um improviso de/com o mundo (DELEUZE; GUATTARI, 21997b) e uma heterotopia literária (FOUCAULT, 2007) e uma força poética (BARROS, 2010) e uma potência de pensamento (AGAMBEN, 2017) e um gesto de profanação (AGAMBEN, 2007) e um neologismo vital (ROSA, 1994) e um jogo de amarelinha (CORTÁZAR, 2015) e um espírito brincante (NIETZSCHE, 2011) e um tempo aiônico (HERÁCLITO, 2017) e... e... e...

Ô máquina de guerra, abra alas ${ }^{\mathrm{xxvi}}$, abra mais alas do que todas as alas que há no mundo e deixa a "ética crianceira" passar!

\section{REFERÊNCIAS}

AGAMBEN, Giorgio. Profanações. São Paulo: Boitempo, 2007.

. A potência do pensamento: ensaios e conferências. Belo Horizonte: Autêntica, 2017.

ARENDT, Hannah. Entre o passado e o futuro. Mauro W. Barbosa. São Paulo: Perspectiva, 2016.

BARBER, Benjamin R. Consumido. Como o mercado corrompe crianças, infantiliza adultos e engole cidadãos. Tradução: Bruno Casotti. Rio de Janeiro: Editora Record, 2009.

BARROS, Manoel. Poesia completa. São Paulo: Leya, 2010.

CALLIGARIS, Contardo. Crianças fora da infância. Folha de S. Paulo, São Paulo, 2 jul. 2009. Disponível em: https://www1.folha.uol.com.br/fsp/ilustrad/fq0207200923.html. Acesso em 25 ago. 2020.

CHIQUITO, Ricardo Santos. Infância, didática, salvacionismo: implicações em torno da arte de ensinar em Comenius. 2014. Tese (Doutorado em Educação) - Faculdade de Educação, Universidade de São Paulo, São Paulo. 2014.

CORTÁZAR, Julio. O jogo da amarelinha. 4. ed. Rio de Janeiro: Civilização Brasileira, 2015.

COSTA, Sylvio de Sousa Gadelha. Governamentalidade neoliberal, Teoria do Capital Humano e Empreendedorismo. Educação \& Realidade, Porto Alegre, v. 34, n. 2, p. 171-186, 2009. Disponível em https://seer.ufrgs.br/educacaoerealidade/article/view/8299/5537. Acesso em 02 set. 2020 .

CRIANÇA, a alma do negócio. Direção de Estela Renner. São Paulo: Marcos Nisti e Maria Farinha Produções, 2008. 1 DVD (50min.), son., color.

DELEUZE, Gilles. Conversações, 1972-1990. Tradução de Peter Pál Pelbart. São Paulo: Ed. 34, 2013.

Revista Interinstitucional Artes de Educar. Rio de Janeiro, V. 7, N. 1 - pág. 60-81 janeiro-abril de 2021: "Pedagogias Vitais: Corpo, Desejo e Educação" DOI: 10.12957/riae.2021.54910 
Crítica e clínica. Tradução Peter Pál Pelbart. São Paulo: Editora 34, 2011.

DELEUZE, Gilles; GUATTARI, Félix. Kafka: por uma literatura menor. 1. ed. Belo Horizonte: Autêntica Editora, 2014.

. Mil platôs: capitalismo e esquizofrenia. v. 4. Tradução Suely Rolnik. Rio de Janeiro: Ed. 34, 1997a.

v. 5. Tradução Peter Pál Pelbart e Janice Caiafa. Rio de Janeiro: Ed. 34, 1997 b.

v. 1. Tradução Aurélio Guerra Neto et al. Rio de Janeiro: Ed. 34, 2000.

Ed. 34, 2011.

O Anti-Édipo: capitalismo e esquizofrenia. Tradução Luiz B. L. Orlandi. São Paulo:

O que é a filosofia? Tradução Bento Prado Jr. E Alberto Alonso Muñoz. São Paulo: Editora 34, 1992.

DELEUZE, Gilles; PARNET, Claire. Diálogos. Tradução Eloisa Araújo Ribeiro, São Paulo: Escuta, 1998.

FOUCAULT, Michel. O sujeito e o poder. In: DREYFUS, H.; RABINOW, P. (org.). Michel Foucault, uma trajetória filosófica: para além do estruturalismo e da hermenêutica. Rio de Janeiro: Forense Universitária, 1995b. p. 231-249.

O cuidado com a verdade. In: . Ética, sexualidade e política. Tradução Elisa Monteiro e Inês A. D. Barbosa. 2. ed. Rio de Janeiro: Forense Universitária, 2006. (Ditos e escritos, v. 5).

Dits et écrits II, 1976-1988. Editado por Daniel Defert e François Ewald. Paris : Éditions Gaillimard, 2001.

. As palavras e as coisas: uma arqueologia das ciências humanas. Tradução Salma Tannus Muchail. 9. ed. São Paulo: Martins Fontes, 2007.

. Nascimento da biopolítica: curso dado no Collège de France (1978-1979). Tradução Eduardo Brandão. São Paulo: Martins Fontes, 2008.

FURTADO, Beatriz; LINS, Daniel. Fazendo rizoma. São Paulo: Hedra, 2008.

GADELHA, Sylvio de Souza. Governamentalidade neoliberal e instituição de uma infância empreendedora. In: KOHAN, Walter Omar. Devir-criança da filosofia: infância da educação. Belo Horizonte: Autêntica Editora, 2010. p. 123-138.

GONZAGA, Chiquinha. Ô Abre Alas!. Novoson SL, 2018. Disponível em $<$ https://open.spotify.com/track/5BNU57NCH9C9mwpRPcoyrV?si=KSHVZV37QOyRIoFc mdxF5A > . Acesso em 20 ago. 2020. 
GROS, Frédéric. Desobedecer. Tradução Celia Euvaldo. São Paulo: Ubu Editora, 2018.

HERÁCLITO. Os pensadores originários. Tradução de Emmanuel Carneiro Leão e Sérgio Wrublewski. Petrópolis, RJ: Vozes, 2017.

HOUAISS, Antônio; VILLAR, Mauro de Salles. Dicionário Houaiss da língua portuguesa. 1. ed. Rio de Janeiro: Objetiva, 2009.

KATZ, Chaim Samuel. Crianceria: o que é a criança. Cadernos de Subjetividade, São Paulo, v.1, n.1, p. 91-98. 1993.

KOHAN, Walter Omar. Apontamentos filosóficos para uma (nova) política e uma(também nova) educação da infância. In: Reunião ANPED, 27, 2004, Caxambu/MG. Anais eletrônicos. Rio de Janeiro: ANPED, 2004. Disponível em www.anped.org.br/27ra.htm. Acesso em 10 set. 2020.

KOHAN, Walter Omar. Visões da Filosofia: Infância. Alea, Rio de Janeiro, v.17, n. 2, p. 216226, dez. 2015. Disponível em: http://www.scielo.br/scielo.php?script=sci_arttext\&pid=S1517-

106X2015000200216\&lng=en\&nrm=iso. Acesso em 22 ago. 2020.

LINS, Daniel. Mangue's school ou por uma pedagogia rizomática. Revista Educação e Sociedade, Campinas, vol. 26, n. 93, p. 1229-1256, set./dez. 2005.

. Nietzsche: vida nômade: estadia sem lugar. In: MARQUES, Davina; GIRARDI,

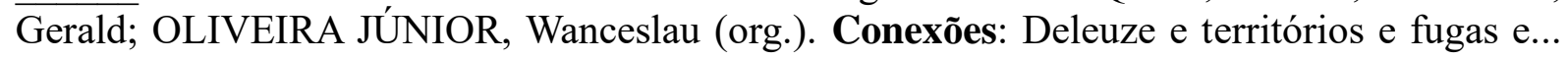
Petrópolis, RJ: De Petruset Alii; Campinas, SP: ALB; Brasília, DF: Capes, 2014. p. 139-161.

Revista Lampejo, Fortaleza, v. 6, n. 2, p. 271-286, jul./dez. 2017.

MARCHI, Rita de Cássia. Os sentidos (paradoxais) da infância nas ciências sociais: um estudo de sociologia da infância crítica sobre a "não-criança" no Brasil. 2007. Tese (Doutorado em Sociologia Política) - Universidade Federal de Santa Catarina, Centro de Filosofia e Ciências Humanas, Programa de Pós-Graduação em Sociologia Política. 2007

MILL, Daniel (org.). Escritos sobre educação: desafios e possibilidades para ensinar e aprender com as tecnologias emergentes. São Paulo: Paulus, 2013.

NIETZSCHE, Friedrich Wilhelm. Assim falou Zaratustra: um livro para todos e para ninguém. Tradução, notas e posfácio de Paulo César de Souza. São Paulo: Companhia das Letras, 2011.

PESSOA, Fernando. Obra poética de Fernando Pessoa: volume 2. 1. ed. 1 Rio de Janeiro: Nova Fronteira, 2016.

ROSA, João Guimarães. Grande Sertão: veredas. Rio de Janeiro: Nova Aguilar, 1994.

RIZZO, Luisa; FONSECA, Tânia Mara Galli da. O acontecimento patchwork - um modo de apreender a vida. Psicologia \& Sociedade, v. 21, n. 1, p. 139-148. 2010. 
SAMPAIO, Helena Almeida e Silva. Olhei uma infância a desabar sobre uma criança: fotografei o sobre. 2019. Dissertação (Mestrado em Educação) - Programa de Pós-Graduação em Educação, Centro de Ciências de Educação, Artes e Letras, Universidade Regional de Blumenau, SC, 2019.

SÓ dez por cento é mentira: a desbiografia de Manoel de Barros. Direção de Pedro Cezar. Rio de Janeiro: Artezanato Eletrônico, 2009. 1 DVD (80 min.), son., color.

SOUZA, Elton Luiz Leite de. As zonas de vizinhança. 26 out. 2015. Disponível em: http://multitudopoesiaartefilosofia.blogspot.com/2015/10/as-zonas-de-vizinhanca.html. Acesso em 6 set. 2020.

TRIBALISTAS. Carnavalia. EMI Brasil, 2002. Disponível em: https://open.spotify.com/track/18fTEyZ41dkbaZLFkWi1UK?si=LgUgGuaXRxuWZ_2Cn0bb 7A. Acesso em 20 ago. 2020.

VEIGA-NETO, Alfredo. A facilidade de se fazer algo difícil ou, se quisermos, a dificuldade de se fazer algo fácil. In: FOUCAULT, Michel. Do Governo dos Vivos: curso no Collège de France, 1979-1980: excertos. 2a ed. Rio de Janeiro: Achiamé, 2010.

'Doutoranda em Filosofia na Pontifícia Universidade Católica de São Paulo (PUCSP). Mestre em Educação pela Universidade Regional de Blumenau (FURB). Integrante do grupo de pesquisa Saberes de Si. Possui graduação em Pedagogia pela Universidade Federal do Paraná (UFPR/ 2008) e graduação em Ciências Biológicas pela Pontifícia Universidade Católica do Paraná (PUCPR/ 2007). Pesquisa Infâncias poéticas e filosóficas e suas implicações ético-estéticas, políticas e ontológicas. Mãe de dois filhos, teve licença maternidade em 2014 e 2016. Brasil. ORCID: https://orcid.org/0000-0001-6639-8670

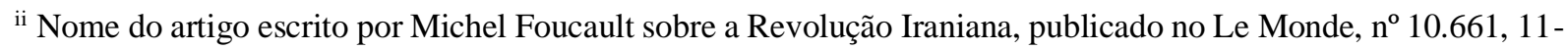
12 de maio de 1979, p. 1-2.

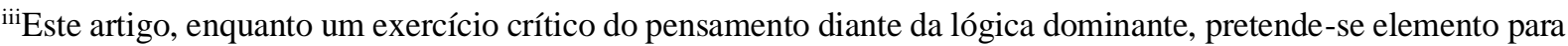
compor "barreiras" a esse poder. Ele faz parte de um estudo sobre a palavra infância, ou melhor, um estudo em que olhamos uma infância a desabar sobre uma criança - dizendo o que essa criança "é", "deve", "quer" e "pode" - e a partir do qual tentamos pensar máquinas de guerra para que outras infâncias (ou crianças) sejam possíveis. Cf. SAMPAIO, 2019.

iv Sobre a arte de gaguejar, diz Deleuze (2011, p. 138, grifos no original): "não é mais o personagem que é gago da fala, é o escritor que se torna gago da língua: ele faz gaguejar a língua enquanto tal". Para o filósofo, a gagueira seria como um procedimento de escrita desejado e desejável; uma prática de potência criativa.

v Deleuze e Guattari usam as terminologias maior-menor-minoridade, pela primeira vez, no livro "Kafka: Por uma literatura menor" (DELEUZE; GUATTARI, 2014), em 1975, quando propuseram abordar a obra de Kafka como uma "literatura menor", exatamente para marcar como a escrita deste autor contrasta com aquilo que chamam de "literatura maior" - que seria a literatura dos cânones literários, dos grandes mestres. Portanto, por "menor" tomase aquilo que permite, de uma maneira revolucionária, colocar algo (uma produção literária, ou mesmo, um conceito) fora da alçada daquilo que é sinônimo do clássico, do tradicional, do dominante, do "maior".

vi Segundo Kohan (2004), o emprego de "expressões como 'sabe-se que', ou "todos sabemos que", ou "como já sabemos" indicam precisamente os pontos de dormência de uma pesquisa que podem ser explorados. Essas expressões, por vezes singelas, automáticas e descompromissadas, introduzem sub-repticiamente a naturalização 
do saber que, por seu turno, constitui e marca a região do não-pesquisado e do não-pesquisável. A generalização indeterminada e totalizante do saber e da pesquisa ("sabe-se" = "todo mundo sabe") só pode corresponder à anulação do saber e da pesquisa, pois "quando todo mundo sabe, ninguém sabe".

vii Como afirma o próprio Manoel de Barros, no documentário de P. Cezar, Só dez por cento é mentira (2009).

viii Segundo Deleuze (2011, p. 11): "Escrever é um caso de devir, sempre inacabado, sempre em vias de fazer-se, e que extravasa qualquer matéria vivível ou vivida. É um processo, ou seja, uma passagem de Vida, que atravessa o vivível e o vivido. A escrita é inseparável do devir; ao escrever, estamos num devir-mulher, num devir-animal ou vegetal, num devir-molécula, até num devir imperceptível".

ix Sobre a vespa e a orquídea, Deleuze e Guattari (1997a, p. 96) escrevem: "Na linha ou bloco do devir que une a vespa e a orquídea produz-se como que uma desterritorialização, da vespa enquanto ela devém uma peça liberada do aparelho de reprodução da orquídea, mas também da orquídea enquanto ela devém objeto de um orgasmo da própria vespa liberada de sua reprodução. Coexistência de dois movimentos assimétricos que fazem bloco numa linha de fuga onde se precipita a pressão seletiva."

${ }^{x}$ Sobre as metamorfoses nietzschianas do espírito cf. NIETZSCHE, 2011.

xi Como já citado: "Lançamo-nos, arriscamos uma improvisação. Mas improvisar é ir ao encontro do Mundo, ou confundir-se com ele. Saímos de casa no fio de uma cançãozinha" (DELEUZE; GUATTARI, 1997a, p. 123).

xii Menção ao documentário "Criança, a alma do negócio" (2008), dirigido por Estela Renner e produzido por Marcos, no qual há uma importante crítica à forma que uma publicidade sem limites, ética ou regulamentação impulsiona o consumismo exacerbado entre crianças e adolescentes.

xiii Em sua tese de doutoramento, Marchi (2007, p. 230) inaugura tal conceito: “A 'não-criança' seria aquela a quem a infância é negada. Aquele indivíduo a quem embora todas as evidências sociais amplamente reconhecidas lhe outorguem o estatuto de sujeito "menor de idade", e, portanto, com direito ao requisito de "viver a infância", o contexto mais imediato de vida em que se encontra, indica uma desconsideração desta sua condição. Este seria o indivíduo não-portador da condição social da infância, aquele a quem este tempo e espaço social têm sido historicamente negados".

xiv Trago como uma possibilidade afirmativa a negativa original: "As perguntas das crianças são mal compreendidas enquanto não se enxerga nelas perguntas-máquinas; donde a importância dos artigos indefinidos nessas questões (um ventre, uma criança, um cavalo, uma cadeira, "como é que uma pessoa é feita?). O espinosismo é o devir-criança do filósofo" (DELEUZE; GUATTARI, 1997a, p. 44, grifo no original).

xv "Ó Abre Alas" é o nome de uma famosa marchinha de carnaval, composta pela brasileira Chiquinha Gonzaga (2018), em 1899.

xvi "Como o governo da infância, através de uma forma de capital configurado nas crianças, pode servir de meio estratégico ao governo dos indivíduos e coletividades adultos, ou à população geral? Que mecanismos precisam ser mobilizados com esse intuito? E, então, como o consumismo voltado para a infância se acopla a uma engrenagem mais complexa, destinada ao governamento dessa parcela específica da população e, por intermédio deste, ao governamento da população em geral?" (GADELHA, 2010, p.128).

xvii Pausa. Quebra. Desvio. Momento que dá a ver aquilo que afeta esta pesquisadora e mostra algo que faz parte do processo de pesquisa. São considerações que produzem fraturas no fluxo da escrita - e do pensamento - da pesquisa. Também é parte da invenção de "linhas de fuga" diante das pretensas universalidades dos saberes, o que implica em identificar as "linhas de força" e procurar as brechas, virar-se e revirar-se nos possíveis furos e encontrar a possibilidade de "inter-ser", de um intermezzo entre as milhares de convicções sobre a infância, advindas daqueles que "julgam-se os porta-vozes das verdades verdadeiramente verdadeiras" (VEIGA-NETO, 2010, p. 11).

xviii Cabe destacar a escolha pela grafia da palavra "afecto", para marcar o sentido de afetação, diferenciando-a de "afeto", que remeteria ao sentido de afeição.

xix No encontro, Gilles Deleuze e Claire Parnet (1998, p. 14) escreveram: “[...] um encontro é talvez a mesma coisa que devir ou núpcias; é do fundo dessa solidão que se pode fazer qualquer encontro; encontram-se pessoas (e às vezes sem as conhecer nem jamais tê-las visto), mas também movimentos, ideias, acontecimentos, entidades". 
${ }^{x x}$ No prefácio do livro "Conversações", Deleuze (2013) diz: "Por que reunir textos de entrevistas que se estendem por quase vinte anos? Certas conversações duram tanto tempo, que não sabemos mais se ainda fazem parte da guerra ou já da paz. É verdade que a filosofia é inseparável de uma cólera contra a época, mas também de uma serenidade que ela nos assegura. Contudo, a filosofia não é uma Potência. As religiões, os Estados, o capitalismo, a ciência, o direito, a opinião, a televisão são potências, mas não a filosofia. A filosofia pode ter grande batalhas interiores (idealismo - realismo etc.), mas são batalhas risíveis. Não sendo uma potência, a filosofia não pode empreender uma batalha contra as potências; em compensação, trava contra elas uma guerra sem batalha, uma guerra de guerrilha. Não pode falar com elas, nada tem a lhes dizer, nada a comunicar, e apenas mantém conversações. Como as potências não se contentam em ser exteriores, mas também passam por cada um de nós, é cada um de nós que, graças à filosofia, encontra-se incessantemente em conversações e em guerrilha consigo mesmo".

xxi “[...] A filosofia, mais rigorosamente, é a disciplina que consiste em criar conceitos [...]. Criar conceitos sempre novos, é o objeto da filosofia. É porque o conceito deve ser criado que ele remete ao filósofo como àquele que o tem em potência, ou que tem sua potência e sua competência [...]. Que valeria um filósofo do qual se pudesse dizer: ele não criou um conceito, ele não criou os seus conceitos?” (DELEUZE; GUATTARI, 1992, p. 13-14).

xxii A divisão de touceiras (expressão "roubada" da jardinagem), também chamada de divisão de rizomas, é uma das técnicas mais utilizadas para propagação vegetativa de plantas ornamentais, como por exemplo: grama-preta, várias orquídeas, bananeira, etc. Consiste no corte dos rizomas subterrâneos, para gerar novas mudas.

xxiii Trata-se do "mundo como colcha de retalhos" (DELEUZE; GUATTARI, 1997b, p. 184).

xxiv Com Fréderic Gros (2018), pensar na desobediência como uma atitude ética.

${ }^{x x v}$ O fascismo, diz Foucault (2001, p. 134), é: "não somente o fascismo histórico de Hitler e Mussolini - que soube muito bem mobilizar e utilizar o desejo das massas -, mas também o fascismo que está em todos nós, que assombra nossos espíritos e nossas condutas cotidianas, o fascismo que nos faz amar o poder, desejar essa coisa mesmo que nos domina e nos explora".

xxvi Vale notar que "ala" além de significar "fila, fileira, alinhamento", em sua origem etimológica na palavra latina "ala, ae", também significava "asa" (HOUAISS; VILLAR, 2009, p. 79). Assim, a máquina de guerra não só abre as fileiras - como quem parte o mar ao meio -, mas abre asas para um voo filosófico-conceitual, um exercício do pensamento que traça linhas de voo. 